Saudi Journal of Medicine

Abbreviated Key Title: Saudi J Med ISSN 2518-3389 (Print) |ISSN 2518-3397 (Online)

\title{
Evaluation of Serum Lipid Profile and Oxidative Stress Markers of Wistar Rats Treated with Extract of Momordica Charantia
}

\author{
Chibuike Obiandu $^{1^{*}}$, Prince N. Achinike ${ }^{1}$, Karibo Okari ${ }^{2}$ and Adesua C. Obiandu ${ }^{3}$ \\ ${ }^{1}$ Department of Human Physiology, Faculty of Basic Medical Sciences, University of Port Harcourt, Nigeria \\ ${ }^{2}$ Department of Medical Biochemistry, Faculty of Basic Medical Sciences, University of Port Harcourt, Nigeria \\ ${ }^{3}$ Post Primary Schools Board, Port Harcourt, Rivers State, Nigeria
}

DOI: $10.36348 /$ sjm.2020.v05i02.001

| Received: 14.01.2020 | Accepted: 29.01.2020 | Published: 07.02.2020

*Corresponding author: Chibuike Obiandu

\section{Abstract}

This study was carried out to investigate the antioxidant and serum lipid effects of the leaf extract of Momordica charantia on male wistar rats. The animals were divided into three (3) groups of six (6) rats each. Group one (1) served as control and received distilled water. Group two (2) and group three (3) were treated with $200 \mathrm{mg} / \mathrm{kg} \mathrm{bw}$ and $400 \mathrm{mg} / \mathrm{kg}$ bw of the hydromethanol extract respectively. Extract was orally administered once daily for 30 days. The results obtained showed that the extract caused a significant increase in the catalase and gluthathione enzyme activity and a significant reduction of malondialdehyde level. There were no significant alterations of low density lipoprotein cholesterol (LDL-c), high density lipoprotein cholesterol (HDL-c), triglyceride and total cholesterol concentrations. The lipid ratios like the Castelli's Risk Index I and II were not affected. This study showed that, the leaf extract of Momordica charantia demonstrated anti-oxidant effects but did not influence risk ratios for developing cardiovascular diseases in wistar rats.

Keywords: Momordica charantia, antioxidant, serum lipids, hydromethanol, wistar rats.

Copyright @ 2020: This is an open-access article distributed under the terms of the Creative Commons Attribution license which permits unrestricted use, distribution, and reproduction in any medium for non-commercial use (NonCommercial, or CC-BY-NC) provided the original author and source are credited.

\section{INTRODUCTION}

There has been a tremendous increase in the population of people using medicinal plants for prevention and treatment of various illnesses around the world. This practice is deep rooted in developing countries where a large proportion of the people depend on these natural products to improve their health and well-being. In Africa, these plants are easily accessible and cost effective making them very useful resource in basic health care [1]. Momordica charantia (M.charantia) which is also referred to as bitter melon or bitter gourd is native to the tropics but also a subtropical plant with an edible fruit, and widely grown in Africa, China, Southern and South eastern Asia, etc. In Bangladesh, $M$. charantia is one of the most popular cucurbitaceous vegetable as a result of its nutritive and medicinal value [2]. Several experimental studies carried out with $M$. charantia has documented numerous pharmacological actions of this plant. The findings in some studies showed that, $M$. charantia has antibacterial [3], anticancer [4] and antihypertensive [5] effects.The anti-diabetic effects of this plant was evaluated in alloxan induced diabetic animal models and was found to demonstrate antihyperglycemic effects [6]. In addition, complications are commonly encountered in diabetes leading to irreversible structural and functional changes in various organs [7]. $M$. charantia has shown encouraging results in prevention and delay in progression of diabetic complications such as nephropathy, neuropathy and insulin resistance in experimental animals [8, 9]. Insulin resistance is another important feature of diabetes that is linked to dyslipidemia (Abnormal lipid profile) and atherosclerosis which contribute significantly to morbidity and early mortality [10]. The lipid profile [(total cholesterol (TC), High density lipoprotein cholesterol (HDL-c), Triglyceride (TG) and Low density lipoprotein cholesterol (LDL-c)] analysed after a 12 to 14 hour fast is of great value in identifying cardiovascular risk factors as indicated in the findings from a study which showed that abnormal serum lipids play important role in the development of atherosclerosis in later life [11]. In recent times, research studies has also indicated the involvement of oxidative stress in a number of disease processes, including cardiovascular disease (CVD), atherosclerosis, arthritis, diabetes, cancer etc. [12, 13]. Reactive oxygen and nitrogen species (RO/NS) produced during oxidative stress cause damage to cellular biomolecules, however, several defense 
systems within the cells act to protect the cell and prevent uncontrolled RO/NS increase. Thus, oxidative stress markers are important tools to assess the redox states in biological systems, the presence and progression of disease, and the health-promoting effects of antioxidants in humans. The objective for carrying out this study is to investigate the serum lipid and antioxidant effects of the leaves of $M$. charantia.

\section{MATERIALS AND METHODS \\ Animal models}

Adult male wistar rats used for this study were bred in the animal house of the Faculty of Basic Medical Sciences, University of Port Harcourt, Nigeria. They were placed in standard cages and acclimatized in two weeks while maintaining them in environmental conditions with proper ventilation, 12 hour light and 12 hour dark cycle and free access to food and water. Generally, the procedures conformed to the established principles for the care and use of laboratory animals published by the National Institute of Health, USA [14]. Appropriate institutional approval was obtained for this study.

\section{Preparation of Plant extract}

The leaves of $M$. charantia were obtained from Choba community in Obio Akpor Local Government Area of Rivers State, Nigeria. The plant materials were authenticated by the taxonomist before use. The leaves were washed to remove any dirt on it and later dried. The dried leaves were blended to fine powder and extraction was carried out using the soxhlet apparatus with hydromethanol (1:4) as solvent, at $60-$ $70^{\mathrm{OC}}$. The solution was filtered after 24 hours and the filtrate concentrated under reduced pressure of $60^{\circ \mathrm{C}}$ to a semi solid form using the rotary evaporator. The extract was preserved in a refrigerator at $4{ }^{\mathrm{OC}}$. Serial dilutions of the extracts were made to obtain concentration of $200 \mathrm{mg}$ per $\mathrm{ml}$ of solution for animal oral treatment.

\section{Experimental design/procedure}

This study was designed to investigate the antioxidant and lipid effects of the leaf extract of $M$. charantia. Male wistar rats were divided into 3 groups of 6 rats each. Group one (1) which served as control received distilled water. Group 2 received 200mg/kg bw and group 3 received $400 \mathrm{mg} / \mathrm{kg}$ bw of the hydromethanol leaf extract of $M$. charantia. The extracts were administered orally as single daily doses throughout the period of the experiment using appropriate animal feeding tube. Administration lasted for 30 days. The rats were sacrificed under chloroform anaesthesia, after 24hours of last administered dose.

For estimation of serum lipid profile [Total cholesterol (TC), Triglyceride, High density lipoprotein-cholesterol (HDL-c)], blood was collected through cardiac puncture into appropriate sample tubes. After collection, the samples were centrifuged for twenty minutes in a serologic manual centrifuge. Then, $1 \mathrm{~mL}$ aliquots of serum were removed and used to perform the biochemical assay. In analysing biochemical parameters, commercial Labtest Diagnostic kits were used, with standard techniques based on enzymatic and colorimetric methods, spectrophotometry, in accordance to the manufacturer's recommendations. The concentrations were determined by use of an automatic biochemical analyzer. The determination of Low density lipoprotein-cholesterol (LDL-c) was calculated using the Friedewald formula. The plasma was used for the estimation of oxidative stress biomarkers in accordance with standard methods [15-20].

\section{STATISTICAL ANALYSIS}

For the statistical analysis, SPSS software, version 20.0 was used. We calculated the Mean and standard error of mean (SEM). In the comparison of the mean level of serum lipids and plasma antioxidants between the control and test groups, we used the analysis of variance (ANOVA) and then post hoc test least significant difference. For all crosses whose probability $(P)$ value was less than 0.05 were considered statistically significant.

\section{RESULT}

The result for the study is presented in tables $1-4$.

Table-1: Mean level of Gluthathione and Superoxide dismutase activity.

\begin{tabular}{|l|c|c|c|c|}
\hline \multirow{2}{*}{$\begin{array}{l}\text { Eroups/ } \\
\text { Extracts (mg/kg) }\end{array}$} & \multicolumn{4}{|c|}{ Oxidative stress markers } \\
\cline { 2 - 5 } & Gluthathione ( $\boldsymbol{\mu g} / \mathbf{m i n} / \mathbf{m g}$.protein) & $\%$ Change & $\begin{array}{c}\text { SOD } \\
\text { (Ug/mg.protein) }\end{array}$ & \% Change \\
\hline Control & $0.88 \pm 0.04$ & 0 & $0.12 \pm 0.01$ & 0 \\
\hline 200 & $0.91 \pm 0.11$ & 3.41 & $0.13 \pm 0.01$ & 8.33 \\
\hline 400 & $1.37 \pm 0.16^{*}$ & 55.68 & $0.14 \pm 0.01$ & 16.66 \\
\hline
\end{tabular}

Values expressed as Mean \pm SEM. $\mathrm{n}=6$. Significant at $[*(\mathrm{P}<0.05)]$ when compared to control group 
Table-2: Mean level of Malondialdehyde and Catalase activity

\begin{tabular}{|l|c|c|c|c|}
\hline \multirow{2}{*}{\begin{tabular}{l} 
Eroups/racts (mg/kg) \\
\cline { 2 - 5 }
\end{tabular}} & \multicolumn{4}{|c|}{ Oxidative stress markers } \\
\cline { 2 - 5 } & MDA (Umol/mg.protein) & \% Change & $\begin{array}{c}\text { Catalase } \\
\text { (Units/mg.protein) }\end{array}$ & \% Change \\
\hline Control & $0.72 \pm 0.02$ & 0 & $3.85 \pm 0.55$ & 0 \\
\hline 400 & $0.63 \pm 0.01^{*}$ & -12.50 & $3.56 \pm 0.37$ & -7.53 \\
\hline
\end{tabular}

Values expressed as Mean \pm SEM. $\mathrm{n}=6$. Significant at $[*(\mathrm{P}<0.05)]$ when compared to control group

Table-3: Effect of leaf extract of M.charantia on the serum lipid profile

\begin{tabular}{|l|c|c|c|c|}
\hline \multirow{2}{*}{$\begin{array}{l}\text { Groups/ } \\
\text { Extracts (mg/kg) }\end{array}$} & \multicolumn{4}{|c|}{ Serum lipid profile (mg/dd) } \\
\cline { 2 - 5 } Control & Total cholesterol & Triglyceride & LDL-c & HDL-c \\
\hline 200 & $3.20 \pm 0.21$ & $1.10 \pm 0.08$ & $1.29 \pm 0.06$ & $1.33 \pm 0.08$ \\
\hline 400 & $3.33 \pm 0.32$ & $0.89 \pm 0.08$ & $1.25 \pm 0.08$ & $1.55 \pm 0.17$ \\
\hline & $4.13 \pm 0.66$ & $1.11 \pm 0.15$ & $1.19 \pm 0.17$ & $1.35 \pm 0.07$ \\
\hline
\end{tabular}

Table-4: Mean values of the lipid ratio

\begin{tabular}{|l|l|l|l|l|l|l|}
\hline \multirow{2}{*}{$\begin{array}{l}\text { Groups/ } \\
\text { Extracts (mg/kg) }\end{array}$} & \multicolumn{7}{|c|}{ Lipid ratio (mg/dl) } \\
\cline { 2 - 7 } & $\begin{array}{l}\text { TG/ } \\
\text { HDL-c }\end{array}$ & $\begin{array}{l}\text { TC/ } \\
\text { HDL-c }\end{array}$ & $\begin{array}{l}\text { LDL-c/ } \\
\text { HDL-c }\end{array}$ & $\begin{array}{l}\text { LDL-c/ } \\
\text { TC }\end{array}$ & $\begin{array}{l}\text { LDL-c/ } \\
\text { TG }\end{array}$ & $\begin{array}{l}\text { HDL-c/ } \\
\text { LDL-c }\end{array}$ \\
\hline Control & $0.83 \pm 0.06$ & $2.41 \pm 0.13$ & $0.99 \pm 0.08$ & $0.42 \pm 0.04$ & $1.22 \pm 0.14$ & $1.05 \pm 0.08$ \\
\hline 200 & $0.63 \pm 0.11$ & $2.29 \pm 0.31$ & $0.91 \pm 0.19$ & $0.40 \pm 0.05$ & $1.46 \pm 0.15$ & $1.28 \pm 0.19$ \\
\hline 400 & $0.82 \pm 0.09$ & $3.04 \pm 0.40$ & $0.91 \pm 0.17$ & $0.32 \pm 0.07$ & $1.15 \pm 0.22$ & $1.44 \pm 0.43$ \\
\hline
\end{tabular}

Values expressed as Mean \pm SEM. $\mathrm{n}=6$.

\section{DISCUSSION}

The assessment of antioxidant properties of a plant extract is an interesting and useful task, as it is particularly concerned with finding potential new sources of natural antioxidants that acts as functional food products. In this study, there was a significant $(p<0.05)$ increase in the activity of gluthathione reductase enzyme (Table 1 ). The superoxide dismutase enzyme activity was not significantly affected but the catalase (Table 2) enzyme activity was increased for the group treated with the higher dose $(400 \mathrm{mg} / \mathrm{kg})$ of Momordica charantia extract. This can be observed in the result when the measured enzyme activity in the test group is compared to control. The increase in these enzyme activities implies that leaf extract of Momordica charantia are capable of boosting the antioxidant production in the experimental animals.

The Malondialdehyde (MDA) level was significantly $(\mathrm{p}<0.05)$ reduced in the group treated with $200 \mathrm{mg} / \mathrm{kg}$ of extract (Table 2) when test groups were compared to control. The lower dose $(200 \mathrm{mg} / \mathrm{kg})$ and higher dose $(400 \mathrm{mg} / \mathrm{kg})$ of Momordica charantia extract caused a $12.50 \%$ and $5.56 \%$ reductions in MDA level, respectively. MDA is a product of lipid peroxidation. Lipid peroxidation is considered a useful indicator of reactive oxygen species-mediated damage to cell membranes. MDA is an important end-product of peroxidation of polyunsaturated fatty acids and is frequently used in determination of oxidative stress conditions [21]. Oxidative stress often results from an imbalance between the production of reactive oxygen species and ability of the antioxidant systems to detoxify them.

The antioxidant property of many plants has been attributed to the presence of certain phenolic compounds such as flavonoids and phenolic acids which are reportedly main anti-oxidative compounds of fruits and vegetables. Phenols, flavonoids and tannins are good antioxidants useful in prevention or control of oxidative stress and related disorders [22, 23]. Although, we did not carry out a phytochemical analysis of the extract, but these compounds were discovered in the leaf extract of Momordica charantia in an earlier study [24], and may be responsible for its antioxidant actions. The ability of Momordica charantia to inhibit lipid peroxidation may be due to a free radical scavenging action which prevented further peroxidation and possible damage to cell.

In this study, there was no significant $(\mathrm{p}<0.05)$ change in the level of serum total cholesterol, LDL-c, HDL-c and triglyceride concentrations, when test groups were compared to control. The findings in this study do not agree with the report showing that extract of Momordica charantia reduced triglyceride and LDL-c while increasing HDL-c in animal models [25]. The differences in findings may be due to the different methods of extraction used.

The lipid profile is usually considered in the evaluation of dyslipidemia. Interestingly, the extract neither affected the LDL-c whose elevation in serum is considered atherogenic, nor causes an increase in HDL- 
c which is regarded as cardioprotective [26, 27]. Although, in a human study [28] on the effects of Momordica charantia on lipid profile, there was a reported significant decrease in LDL-c but a nonsignificant change in TC, HDL-c and triglyceride concentrations.

There was no significant $(\mathrm{p}<0.05)$ alterations of the Castelli's risk index-I (CRI-I) [TC/HDL-c] and Castelli's risk index-II (CRI-II) [LDL-c/HDL-c] (Table 4) as well as other cardiovascular risk indices in this study. But a high CRI-I and CRI-II has been associated with higher risk of Ishaemic heart disease. These lipid ratios are often used as an alternative diagnostic tool to predict risk of developing cardiovascular disease [29], even when conventional lipid parameters appear normal.

\section{CONCLUSION}

The leaf extract of Momordica charantia has the potential to inhibit lipid peroxidation due to the reduction in production of malondialdehyde. The extract did not exert significant effects on the lipid parameters and lipid ratios such as the Castelli's Risk Index I and II.

\section{REFERENCES}

1. Chilpa, R., Baggio, C.H., Solano, A.D., Muniz, E., Kauffman, F.C., Sanchez., R.I. (2006). Inhibition of gastric $\mathrm{H}+, \mathrm{K}+-\mathrm{ATPa} e$ activity by flavonoids, coumarins and xanthones isolated from Mexican medicinal plants. Journal of Ethnopharmacology.105:167-172.

2. Islam, Q. M. S., M. Mohiuddin, M. G. Rabbaniand., A. F. Mollah. (2013). Economic Impact of IPM Technology on Bitter Gourd Production in Selected Areas of Bangladesh. International Journal of Applied Research in Business Administration \& Economics, 2(6), 2-8.

3. Khan, M.R. (1998). Momordica charantia and Allium sativum: broad spectrum antibacterial activity. Korean Journal of Pharmacognosy, 29, $155-158$.

4. Khan, S. (2007). Bitter gourd (M. charantia): a potential mechanism in anti-carcinogenesis of colon. World J. Gastroenterol, 13: 1761-62.

5. Ojewole, J.A., Adewole S.O., \& Olayiwola, G. (2006) Hypoglycaemic and hypotensive effects of M. charantia Linn (Cucurbitaceae) whole-plant aqueous extract in rats. Cardiovasc. J. S. Afr. 17: 227-32.

6. Kar, A., Choudhary, B.K., Bandyopadhyay, N.G. (2003). Comparative evaluation of hypoglycaemic activity of some Indian medicinal plants in alloxan diabetic rats. Journal of Ethnopharmacology, 84, 105-108.

7. American Diabetes Association. (1998). Screening for type 2 diabetes. Diabetes Care, 21, S20-S31.

8. Grover J.K., Vats V., Rathi SS., Dawar R., (2001). Traditional Indian antidiabetic plants attenuate progression of renal damage in streptozotocin induced diabetic mice. Journal of Ethnopharmacology 76, 233-238.

9. Rathi, S.S., Grover, J.K., Vikrant, V., Biswas, N.R., (2002). Prevention of experimental diabetic cataract by Indian Ayurvedic plant extracts. Phytotherapy Research. 16, 774-777.

10. Reaven, G.M., (1988). Role of insulin resistance in human disease. Diabetes 37, 1595-1607.

11. Carreras, G., Ordoñez, J. (2007). Adolescence, physical activity, and metabolic cardiovascular risk factors. Rev Esp. Cardiol, 60(6):565-8.

12. Peluso, I., Morabito, G., Urban, L., Ioannone, F., \& Serafi, M. (2012). Oxidative stress in atherosclerosis development: the central role of LDL and oxidative burst. Endocrine, Metabolic \& Immune Disorders-Drug Targets (Formerly Current Drug Targets-Immune, Endocrine \& Metabolic Disorders), 12(4), 351-360.

13. Pietraforte, D., Vona, R., \& Marchesi A. (2014). "Redox control of platelet functions in physiology and pathophysiology," Antioxidants \& Redox Signaling, 21(1):177-193.

14. National Institutes of Health. (1985). Guide for the care and use of laboratory animals. National Academies.

15. Wasowicz, W., Neve, J., \& Peretz, A. (1993). Optimized steps in fluorometric determination of thiobarbituric acid-reactive substances in serum: importance of extraction $\mathrm{pH}$ and influence of sample preservation and storage. Clinical chemistry, 39(12), 2522-2526.

16. Condezo-Hoyos, L., Rubio, M., Arribas, S. M., España-Caparrós, G., Rodríguez-Rodríguez, P., Mujica-Pacheco, E., \& González, M. C. (2013). A plasma oxidative stress global index in early stages of chronic venous insufficiency. Journal of vascular surgery, 57(1), 205-213.

17. Peskin, A. V., \& Winterbourn, C. C. (2017). Assay of superoxide dismutase activity in a plate assay using WST-1.Free Radical Biology and Medicine, 103, 188-191.

18. Vives-Bauza, C., Starkov, A., \& Garcia-Arumi, E. (2007). Measurements of the antioxidant enzyme activities of superoxide dismutase, catalase, and glutathione peroxidase.Methods in cell biology, 80, 379-393.

19. Slaughter, M. R., \& O’Brien, P. J. (2000). Fullyautomated spectrophotometric method for measurement of antioxidant activity of catalase. Clinical biochemistry, 33(7), 525-534.

20. Goldberg, D. M. (1984). Glutathione reductase. Methods of enzymatic analysis, 3, 258265.

21. Raghavendran, H. R. B., Sathivel, A., \& Devaki, T. (2004). Hepatoprotective nature of seaweed alcoholic extract on acetaminophen induced hepatic oxidative stress. Journal of health science, 50(1), 42-46. 
22. Brown, J. E., \& Rice-Evans, C. A. (1998). Luteolin-rich artichoke extract protects low density lipoprotein from oxidation in vitro. Free radical research, 29(3), 247-255.

23. Vinson, J. A., Hao, Y., Su, X., \& Zubik, L. (1998). Phenol antioxidant quantity and quality in foods: vegetables. Journal of agricultural and food chemistry, 46(9), 3630-3634.

24. Jonathan, S. G., Olawuyi, O. J., Aina, D. A., Odeniyi, S. O., Adediji, I. O., \& Ikhedia, A. (2012). Comparative studies on antifungal, anti-oxidant and phytochemical potential of Momordica charantia and Moringa oleifera. New York Science Journal, 5(12), 17-28.

25. Chaturvedi, P., George, S., Milinganyo, M., \& Tripathi, Y. B. (2004). Effect of Momordica charantia on lipid profile and oral glucose tolerance in diabetic rats. Phytotherapy Research: An International Journal Devoted to Pharmacological and Toxicological Evaluation of Natural Product Derivatives, 18(11), 954-956.

26. Juhan-Vague, I., Alessi, M. C., \& Vague, P. (1991). Increased plasma plasminogen activator inhibitor 1 levels. A possible link between insulin resistance and atherothrombosis. Diabetologia, 34(7), 457-462.

27. Gordon, T., Castelli, W. P., Hjortland, M. C., Kannel, W. B., \& Dawber, T. R. (1977). High density lipoprotein as a protective factor against coronary heart disease: the Framingham Study. The American journal of medicine, 62(5), 707-714.

28. Kinoshita, H., \& Ogata, Y. (2018). Effect of bitter melon extracts on lipid levels in Japanese subjects: a randomized controlled study. Evidence-Based Complementary and Alternative Medicine, 2018.

29. Criqui, M.H., Golomb, B.A. (1998). Epidemiologic aspects of lipid abnormalities. Am J Med. 105:48S$57 \mathrm{~S}$. 